\title{
On the concept of the deceptive trailer: Trailer as paratext and multimodal model of film
}

\author{
Martin Oja \\ Department of Semiotics \\ University of Tartu \\ Jakobi 2, 51005 Tartu, Estonia \\ e-mail: martino@ut.ee
}

\begin{abstract}
The goal of the article is to contribute to the basic framework of the semiotic study of film trailers, approaching the trailer as a model of film. Discussing the signifying relations between the trailer and the film, I clarify mechanisms through which meta- or paratexts model their source texts and shape their reception. As examples, two cases in which trailers appear to be deceptive about the film's genre are closely looked upon as the multimodal construction of the trailers of Alejandro G. Iñarritu's Birdman and Nicolas Winding Refn's Only God Forgives is analysed. Following Lisa Kernan and Keith Johnston, the film's genre is seen as the central type of information communicated by the trailer. In this context, genre is understood as dominant in the sense of Roman Jakobson. I propose dominant as the crucial concept: examining incoherences between the dominants of the film and its trailer makes it possible to conduct a closer analysis of the misleading model-making and to predict possible disappointment in the viewing experience.
\end{abstract}

Keywords: film trailers; semiotic models; dominant; multimodality; paratext; deceptive marketing

\section{Introduction}

Film trailers have a double identity. On the one hand, a trailer can be seen as a meta- or paratext, surrounding, supporting and sometimes subverting film by modifying its reception. On the other hand, the trailer has recently emerged as an independent text form. This article will study the trailer in its former, more traditional role. This view allows us to employ a dynamic approach that recognizes the trailer as a part of a larger textual whole of the film, as well as a partially autonomous text on the margins of the source text. From a semiotic perspective, the relation between a film and its trailer can be seen as a relation in which one 
text acts as an object and the other as its model, with characteristic ways of construction, purpose and rhetoric.

The aim of this paper is to shed light upon the workings of the trailer as a model of the film, testing the theoretical assumptions in the case in which the trailer gives an erroneous impression about the film's genre, inducing confusion and leading viewers astray. We can assume that trailers, as commercial texts with the purpose of marketing, have the propensity of presenting films in a deliberately attractive manner. Thus, due to their rhetorical characteristics, trailers have an essential tendency to engage in deceptive modelling to varying degrees.

The central notion of the theoretical background of this paper is the concept of the dominant, following the tradition of Roman Jakobson. I will employ the concept on two levels: firstly, detecting the dominant would be concerned with the type of information the trailers convey in a general sense, that is, whether the message of a certain trailer is focused on the genre, on an actor, an element of a story, or a new technological invention (from among the options Lisa Kernan and Keith Johnston suggest). Secondly, I will be concerned with the question which elements fill the dominant position given on the first level. For instance, if the trailer's message implicates genre, it is obvious to indicate what specific genres are communicated.

A relation between the film and the trailer as two distinct, though partially interrelating and intersecting sign systems, can be described either in terms of intrasemiotic $^{4}$ translation (Dusi 2015: 155) or model-making. I suggest that both mechanisms of meaning generation are similar: the trailer as a model presents some aspects of the film and leaves others aside. This mechanism is not limited to advertisement and promotion, but fundamentally underlies the representation of social reality, starting from personal self-representations in everyday communication, and ending with documentary films or other nonfiction narratives.

This two-level framework gives us the basis for analysis. Considering the trailer as an intrasemiotic translation or a model that is constructed out of the same material as its object, it is a relatively simple task to detect and compare the dominants of a film and its trailer on both levels. I propose that incoherence between the film's and the trailer's dominants will lead to the case of the deceptive trailer: consequently, viewers may experience false expectations and disappointment.

4 Dusi derives the notion on the basis of Roman Jakobson's 'intralinguistic translation', where the process of interpretation uses the signs of the same language or sign system as the original text, i.e. the model is made of the same material as its reference object (Dusi 2015: 162; Torop 2002: 595; Jakobson 1959: 233). 
In this framework, the viewer's sense-making capabilities also have an important position. In the reactions and meanings established by the viewer we can see the logical terminal station of the signifying process. Therefore I have added, as reflexive documents, some online comments of viewers, providing opinions about the success or failure of Birdman, Only God Forgives as well as their trailers. Sometimes these comments include simple, but valuable assessments of the reasons behind these successes and failures.

As the cases of deceptive trailers illustrate, trailer-making practices may create models that modify the meaning of their objects. This naturally assumes multiple, sometimes conflicting human intentions. That, in turn, leads us to the question who makes trailers.

Nowadays, most trailers are not made by the same people who make films. According to David Malki ${ }^{5}$, a veteran in Hollywood film advertising, film marketing is usually divided between the studio's in-house marketing department and one or several outside agencies called trailer-houses. Some trailer-houses specialize in commercials, posters and billboards, others do all sorts of film and design work (commercials, main title sequences, network branding, etc.). Trailerhouses employ writers, producers, editors and animators. In addition, they may hire freelancers for particular projects. During their work, editors usually consult with the in-house producers and clients during the work process. Malki notes that the changes requested by the client may be content-related ("I did not get this joke, make it more clear") or marketing-related ("show more of the baby, moms like the baby") or logistical ("we cannot license that music, find another song to use") (Malki 2009). Thus the work of trailer-making is not an activity of a single authorship, but a collective effort.

Matt Brubaker, an executive of a leading trailer company Trailer Park, points out that creating a trailer starts from a script coming from the filmmakers. ${ }^{6}$ Usually, the trailer team gets the first rough cut from the studio, watches it and develops ideas on the basis of it. The studio can omit some material for security reasons. Different studios have particular tastes for how they want to package their product. Some of them give relatively free hands to the trailer company, some want similar results every time, following a fixed formula based on test audiences

5 Malki, David 2009. Breaking into Trailers. Some Advice about How to Become a MovieTrailer Editor. Webpage. Available: http://davidmalki.com/editor/breakingin.html (accessed 17 May 2017).

6 Patches, Matt 2013. How a movie trailer is made: Behind-the-scenes of Dark Knight Rises, Great Gatsby, and more. Hollywood.com. Available: http://www.hollywood.com/movies/howmovie-trailers-are-made-dark-knight-rises-gatsby-pacific-rim-more-57156419/ (accessed 17 May 2017). 
and previous research. As a new trend, the work on trailer starts during the early phases of film production. There are cases when the ideas developed by trailermakers influence the final outcome of film. For instance, making the trailer of Pacific Rim, Trailer Park innovated a sound to accompany giant robot warriors. The director Guillermo del Toro was satisfied with the result and the sound is now an integral part of the film's final sound design.

The above points indicate that trailer-making is a negotiation between different parties. A possible approach (that neatly combines 1930s literary theory with cutting-edge culture studies) might call for Bakhtinian notions of dialogism, polyphony and heteroglossia. Although for Bakhtin authorial speech becomes equal with different social speeches through heteroglossia - the multiplicity of social voices (Bakhtin 1981:263), we can imagine multiple speeches on the level of various authors.

\section{The system and the components: Semiotic relations}

Trailer, a form of cinematic expression not much younger than film itself ${ }^{7}$, still holds a marginal place in film studies. Only in the last decade has the trailer as the key marketing tool for film producers entered the field of interest of academic research. By now, two monographies have been published on the topic by Lisa Kernan (2004) and Keith Johnston (2009). According to my knowledge, clearly semiotic approaches to the trailer have been used only by Nicola Dusi who has studied fan-made spoof trailers as a practice of cultural remixing.

The main reason for this neglect is the trailer's ambiguous position: it does not exactly belong within the boundaries of film text, and does not remain far from it either. Proceeding from Gerard Genette's notion of paratext, the trailer can be seen as a device of special pragmatic status, surrounding and contextualizing, or re-contextualizing the main text, boasting of an ability to mediate between film and its viewer. Dusi (2015: 154) remarks that trailers as paratexts work as reading instructions, providing potential audiences indications about the film's genre and theme, challenging the viewer's curiosity about the film. In Genette's (1997: 38) division of paratexts into peritexts and epitexts - devices inside and outside of the main text, the trailer, as detached from the main body of film, falls under the category of epitext. As Genette (1997: 344) notes, this division is purely

7 The first film trailer is considered to have been shown in 1912, at Rye Beach, New York. After a chapter of the series The Adventures of Kathlyn, a segment of the following part was shown with the words asking the audience what would happen next (Thomas 1966: 10). In a similar manner, trailers were initially shown after the feature, thus getting their name. 
spatial, and nothing precludes the addition of epitext to peritext later, as has been done, for example, by appending authors' interviews to posthumous editions of their books. Likewise, DVDs sometimes include film trailers among other bonus features. As Chuck Tryon (2009: 33) observes, the proximity of film and its trailers allows the viewers realize how the trailers misrepresent the film narrative in order to market it for wider audiences. The juxtaposition of a film and its trailer can be compared to the inspection of the relation between an original text and its remix. Remix theory would provide a complementary description about this specific way of model-making: how the elements of the original text are transposed, rearranged and substituted.

Keith Johnston notes that, until recently, trailers were not regarded as unique creations, bearing marks of an individual voice or producer (Johnston 2009: 2-3). In the last decade, alongside the upsurge of fast internet connections, development of mobile devices and data streaming, the position of the trailer started to change. The changes have not only transformed the way modern trailers are displayed, distributed and consumed by audiences, but also the status of the trailer as text. Online platforms give audiences a level of freedom in the sense of interactivity and control. Viewers can revisit trailers and watch them repeatedly. As Johnston confirms, trailers are no longer specific to cinema or television, as the model of online distribution has raised trailers above the level of advertisement (Johnston 2009: 152). The commercial identity of the trailer is further challenged by spoof trailers made by film fans and distributed via Youtube or other online media platforms.

Daniel Hesford ${ }^{8}$ poses a simple but important question - if fan-made spoof trailers have no commercial purpose, can trailers be considered to be commercial texts at all? This leads us once again to the dynamics between multiple functions of trailer (aesthetic, commercial, social, etc). When the trailer was traditionally thought of as advertisement, the spoof trailer is targeted not at customers, but at audiences, does not serve as a paratext, but as a text. Similarly to the spoof trailer, the commercial trailer also offers a versatile and popular medium through which a filmmaker or editor may create a cinematic performance (Hesford 2013: 6) ${ }^{9}$. This

8 Hesford, Daniel 2013. 'Action... Suspense... Emotion!': The trailer as cinematic performance. Frames Cinema Journal. University of St. Andrews.

Available at: http://framescinemajournal.com/article/action-suspense-emotion-the-trailer-ascinematic-performance (accessed 11 October 2017).

9 The trailer as an experimental art form has a history of its own. Perhaps one of the most significant landmarks in that history is Hitchcock's trailer for Psycho (1960), merging commercial purposes with documentary modality, bringing in the film's director as a narrator or a tour guide at the "crime scene". 
brings forward a significant process: film trailers have gone through the phase of emancipation; now they can be approached as a text type of novel features and borderline status. We can see the trailer as a double-coded entity, switching between the modes of commerce-oriented epitext and a self-sufficient unit of cinematic expression.

A semiotic theory of the trailer's modelling action would contain two complementary methodological approaches. First, we can deal with the trailer as a unitary element in a larger system. In that case, the research task would be describing its relations to the other elements of the same system. What these elements are depends on the breadth of our focus. For example, we could assess a specific trailer among other trailers: starting from its close surroundings, trailers of the same film (if there are several), trailers of the same film genre, the same director, or an era. Or, a trailer can be seen as a unit in the system of different types of paratexts of the same film. In that dimension, our interest would turn to trailer's functional distinctiveness compared with that of film posters, director's interviews, etc. Second, the trailer can be seen as a text and a sign system in its own right. In this case, our object of interest would be its poetics, the relations between its elements.

Both approaches could use the benefits of syntagmatic and paradigmatic analysis.

Describing the trailer as a model of a film, syntagmatic relations between the trailer's constituent units, e.g. shots, sound segments and elements of mise-enscéne, would primarily reveal the dynamics between the model and its users: how the creators of a trailer guide the reception process of its viewers. Paradigmatic relations mostly define dynamics between model (trailer) and its object (film). As such, a paradigmatic study would take notice of which elements are taken from film text and re-established in the trailer. It would also be concerned with the question whether the same elements fulfill the same functions both in the film and in its trailer. Syntagmatic and paradigmatic approaches cannot exist without each other; they are dimensions of one and the same analytical process.

Following the standpoint of the viewer who has seen the trailer and the film in this order, we could take these viewings as a united experience that induces a certain understanding of the film's meaning. Jonathan Gray (2010:2-3) describes how trailers create early frames and filters suggesting to viewers what to think about the film's genre, themes and tone. Thus he explicates that the meaning of a film depends, to a degree, on the fact whether the viewer has seen its trailer or not. Experiencing the trailer and the film in succession means synthesizing elements from the two levels. As a conclusion, this synthesis can be described in terms of Juri Lotman's notion of 'work of art'. 
For Lotman, the meaning of a work of art depends on the relations between the text and the related (sign) systems outside the text. Only in relation with these outside systems is it possible to understand, which are the active elements in the structure of text and which are not (Lotman 2006: 229). Based on this, we may consider film as an external system for the trailer (the meaning of the trailer's elements can be understood only against the background of the film, but not vice versa). In that sense, the relation between the film and the trailer is asymmetrical. The paratextual level does not suffice to pinpoint the dominant meaning generating elements of the film, and we must also consider the wider cultural context for that purpose.

Before we can deal with the questions concerning the elements of the trailer, trailers as elements in a bigger system, and the joint influence of film and its trailer on the viewer, we must address an even more basic question: how does a trailer represent a film? Claiming that the model is made of the same type of material as its object remains too general. In order to answer this question, we need to shed light upon the type of information trailers communicate about films. In cases when the viewers feel that the trailer has represented the film inadequately, the model misrepresents the properties of its object to a degree. The first step of the analysis would be to determine the properties misrepresented.

In order to focus on the relevant properties, I propose the concept of the dominant developed by Roman Jakobson. As Brian McHale and Robert Stam suggest, it originates from Yuri Tynyanov (McHale 1987: 6; Stam 1992: 11). I claim that it is possible to distinguish the dominants of film and its trailer, and test them for correspondence or dissonance. As Kernan and Johnston both agree (see below), genre appears to be one of the most important types of information that is communicated by the trailer. Consequently, in search of the dominants, I propose to concentrate on the signs of genre in trailer and in film, comparing how well these overlap with each other.

\section{The dominant and genre}

The dominant, one of the most constructive concepts in Russian Formalist theory, can be described as the focusing component of a work of art; it manages, determines, and transforms the remaining components. In a sense, the dominant guarantees the integrity of the text's structure. Jakobson claims that the dominant can be sought for not only in the poetic work of an individual artist but also in the art of a given epoch. For instance, the dominant of Renaissance culture was visual art, the dominant of Romanticism was music, the dominant of Realism 
verbal art (Jakobson 1981[1935]: 752). In the context of a certain epoch or culture, the dominant also helps to discern the type of text or message; for instance, the aesthetic function in the position of the dominant in a verbal message makes the latter a poetic work (Jakobson 1981[1935]: 753). Jakobson's understanding of the dominant is quite broad: on the one hand, the dominant of a text can be defined by the formal rules and the structure of the text; on the other hand, it can be specified on the basis of the type of content.

In film, both approaches are conceivable. We could easily recall examples of films that are mostly structured and given meaning to by formal operations such as editing or camera work, and also films that are driven by the content - the theme of the story. In any case, we must keep in mind that those methods of structuring are almost never absolute or exclusive.

Before broaching the problem of genre and looking for the dominant in film trailers, let us take a glance on a couple of those rare occasions when the notion of the dominant has been employed in film theory. In their writings on film, Russian formalist scholars used the term but scarcely. For Boris Eikhenbaum (2013[1927]: 10 ), one of the crucial points defining cinema as a "new syncretic form of art" was its emancipation from the theatre. He writes:

The invention of the movie-camera made possible the exclusion of the basic dominant of theatre syncretism - the audible word, and its replacement by another dominant - the movement observed in details. [...] The film spectator finds himself in completely new conditions for perception. (Eikhenbaum 2013[1927]: 10)

The sign system in which the dominant has structuring capabilities could be as wide as a cultural paradigm, but also a much more constrained entity. Film theorist Ian Aitken interprets the place of the dominant in Eisenstein's early montage theory: the method of Eisenstein's "montage of attractions" initially consisted of linking the dominant aspect of one shot to another, via the principle of attraction montage ${ }^{10}$ (Aitken 2001: 31). Later, Eisenstein revised his theory, placing more emphasis on the ancillary aspects of attraction and regarding the film shot as a locus for different interacting attractions. Thus he discarded the understanding of attraction as merely a vehicle for carrying a dominant theme (Aitken 2001: 31). This development aptly characterizes the limits of the concept

10 Eisenstein claimed that the attraction has nothing in common with the trick or the stunt; the concept was derived from the theatre and it meant aggressive "moves" or the sub-parts of these moves that influence the audience emotionally. These moves were evoked studiously; attractions were providing the audience an opportunity to perceive the ideological aspect of the spectacle or the part of it (Eisenstein 1988[1923]: 34). 
of dominant - in "young", preliminary theories, such a concept justifies itself with its generalizing and reductionist power. Later, when a theory develops into a more detailed framework, the concept has its capabilities diluted. As my article aims to sketch a preliminary semiotic theory of the film trailer, and a framework for understanding its basic meaning generation mechanism, I find the concept of the dominant useful.

In order to give a better view of the modelling process of the trailer, I propose to take a comparative look at the dominants of specific films and their trailers. The trailer can be seen as a type of text that is more concentrated and narrower in its scope. We could suppose that what is present in a trailer could be found, at least in some sense, in the film, but not necessarily vice versa. In that sense, the relation is unidirectional: the model is made of the segments of its object, not the other way round. Starting with the trailer's dominant allows us a prompt comparison, which may get lost when starting with the film's dominant.

Because of the wide scope of the notion of the dominant, another preparatory step is necessary. Before asking what the possible dominants of the film trailer are, we must ask what codes trailers mostly use while engaging viewers. In discussing these problems I am drawing on the works of Lisa Kernan and Keith Johnston.

Kernan, taking mostly an historical perspective, follows the development of the trailer as a rhetorical text through time, which she divides into three periods: the classical, the transitional and the contemporary. She understands trailers mostly as persuasive texts and takes an interest in how trailers address viewers and how they reveal the way the motion picture industry imagines its audiences. Kernan identifies genres, stories and stars as films' three principal rhetorical appeals that are promoted with trailers (Kernan 2004: 5, 14). These appeals are directed at the feeling of the spectator's familiarity with a genre, an actor or an element of a story (Kernan 2004: 14), that is, something that enables a sort of agreement with the viewer, thus acting as a code. Keith Johnston, who sees the trailer, in spite of its being a marketing tool, as a unique audiovisual format, adds a couple of further dimensions, saying that trailers communicate studio-, star-, technology-, and genre-specific messages (Johnston 2009: 3). Hence we have at least three or even more possible codes that can be associated with the dominant, or the locus where the dominant can be searched for.

Genre appears as a pivotal and inevitable code both for Johnston and Kernan. Even if a spectacle (highlighted by Kernan) or a technology (drawn attention to by Johnston) achieved a fundamental position in the trailer's appeal, they seem to mirror the requirements of an underlying genre. For instance in the 1950s, the spectacle-oriented visual imagery started to displace narrative with the development of science-fiction films (Johnston 2009: 23). Stars, likewise, can 
be associated with specific genres, as illustrated by Rick Altman (Altman 1999: 25) and Barry Keith Grant. Grant remarks that Arnold Schwarzenegger's body determined that he would star in action films; the incongruity of the muscular actor appearing in a different generic context such as Kindergarten Cop provided comic nuances (Grant 2007: 19). Although some actors (e.g. Johnny Depp) are known for their chameleon-like performances, most play variations of a type and, for this reason, are often cast in similar films within the same genre (Grant 2007: 18). In such a manner, genre itself seems to work as a dominant code that aligns and controls other codes operating between film producers, film texts and their audiences. Consequently it is no surprise that both trailers analysed below are predominantly deceptive about the films' genre. As models they present their objects in a more marketable light, yet create false expectations.

From my point of view, the crucial property of genre is its ability to work as a code in the communication between filmmakers, distributors, trailer-houses, critics and viewers. Genre as code provides all these parties decisive cues for meaning generation, viewing position and interpretation. Still, genre as a complex concept also has other meanings to be pointed out. In addition to genre as contract (which principally overlaps with code) Altman draws attention to genre's function as blueprint and structure, preceding the film and shaping its production; and genre as label - the name of the category central to the decisions and communications of distributors and exhibitors (Altman 1999: 14).

Paradoxically, as the success of a code relies upon its fixedness, one should be cautious treating genre as static and immutable. Not unlike living organisms, genres can be seen as having their own "evolution" with birth and demise. As other social constructions, genres and their borders are continuously negotiated between different parties (Altman 1999: 62-65, 222). Highlighting genre's volatility is the central point of Altman's treatment. For a more explanatory description of genre as a dynamic semiotic system, I propose a framework elaborated by Juri Lotman and the Tartu-Moscow School.

In Lotman's words, one of the chief sources of a system's dynamism is the constant influx of extrasystematic elements and expulsion of systematic elements; or, inside a system, exchange of elements between the system's nucleus and periphery (Lotman 1977: 196, 205). Acknowledging these dynamics reveals what is necessary for a genre to retain its identity, and also indicates when a wholly new genre must be considered.

Before looking more closely at how trailers (mis)communicate genres, another remark is in order. A trailer can promote various genres at the same time, with the intention of increasing the expected audience and by trying to pitch the film to the largest possible number of viewers. Hollywood publicity often avoids 
concrete genre terms in order to favour ambivalence in terms of the genre (Altman 1999: 54). The rhetoric of "something for everyone" can be expressed within the generalized framework of an individual genre, presenting films' various generic appeals in a manner that leads trailers to construct genre at the same time as they construct genre-transcending commodity-units (Kernan 2004: 15). This playing with the boundaries of genre, simultaneously trying to cross and maintain them, can cause disappointment in viewers.

To conclude, Roman Jakobson's extensive definition of the dominant allows us to consider genre on two levels. First, genre in a general sense functions as the dominant of the trailer, subordinating and organizing the trailer's actor- or technology-based cues. Second, genre in a specific sense, i.e. action, drama, comedy and so forth, organizes the material on the level of film and concurrently pre-organizes it for the trailer. On both levels, genre structures the process of trailer production as model-making.

\section{Constructing the model: From intrasemiotic translation to remixing and multimodal modelling}

Prior to the analysis of the trailers, the article will touch upon the question of how trailers are made into models of films by means of editing. Then it will consider the fact that trailers, as other audiovisual texts, concurrently employ different modes of expression or channels of information (verbal, visual, auditory). This would call for a multimodal approach. But first, the concept of model in the framework of semiotics will be briefly discussed.

I would distinguish two essential ways of characterization of semiotic models. The first focusses on the sign relations between a model and its object. It is represented, most recently, by Winfried Nöth, who elaborates a typology of models based on Peirce's classic division of sign into sign vehicle, its object, and its interpretant. Some important distinctions that Nöth makes can be outlined here: (1) a model represents something or is a type of something (Nöth 2018: 8); (2) as signs can be material or mental objects for Peirce, a model can be either material or mental (Nöth 2018: 9); (3) as models can be built on iconic or symbolic relations, the pure indexicality as a principle of model-making must be left out, for the minimum definition of modelling requires representation, not mere indication (Nöth 2018: 10, 12). This leads Nöth towards making a distinction between models and samples: while a model serves to represent its object domain, the sample does not.

To illustrate sampling, Nöth touches upon a chef's activity of food-tasting and a tailor's use of cloth samples. Although a spoonful of sauce or a cloth sample possess 
the same features as their objects, they do not denote their objects (Nöth 2018: 12, 13). This distinction works properly until we take into account the whole situation of sample use. We have to consider that a sample, though not a model in itself, is attended by a mental framework, containing at least the purpose of sampling. The purpose of sampling can control various evaluative and comparative processes, often requiring mental or material representations of paradigmatic alternatives to the specific sample. Consequently, the mental framework surrounding a sample brings along iconic and symbolic principles. Hence I propose that in most cases the use of samples can still be considered modelling. The issue of samples clearly indicates that the definition and typology of models depend not only on the mode of representation but also on the ways in which models are used.

This leads us to the other view that focusses on the model's function and purpose. As Ladislav Tondl (2000: 84) emphasizes, models have first and foremost been constructed as goal-oriented. The importance of functionality is also behind the relatively broad and general approach to modelling by Juri Lotman and the Tartu-Moscow School (TMS). As Peter Grzybek indicates, in the works of the Tartu-Moscow School the notions of the model and the modelling system are fundamental, leading to the claim that semiotic systems are primarily worldmodelling systems (Grzybek 1994: 286). Still, the TMS have never established a clear position about the relations between the concepts of the model and the sign (resp. modelling system and sign system) (Grzybek 1994: 290). This can render the notion of modelling system general and partially vulnerable to some extent.

When interpreting Lotman's phrase that a model is an analogue of an object of perception that substitutes it in the process of perception (Lotman 2011[1967]:250), we also have to take into account how broad many definitions are in Lotman's semiotics. I would remain doubtful of Nöth's claim that Lotman's 'analogy' automatically suggests that models are iconic signs (Nöth 2018: 35). Neither should the notion of 'perception' refer to iconic representation alone. I see a close connection between Lotman's 'perception' and the omnipresent activity of worldmodelling. Thus I would understand early Lotman's 'analogy' more widely - as something that can be also symbolic. In that case 'analogy' refers to similar internal structures of elements in objects and in models as the corresponding systems.

So I propose, independently of any typology of models, that the main function of models is to let their users perform systematic cognitive operations that can materially or virtually be transferred over to the objects of models in order to manipulate them or understand them better. The systematic property of a model is exemplified in the sense that at least two interconnected elements of the model must be in correlation with respective elements of the model's object. Accordingly, the difference between a simple sign and a model is that a model is already a 
sign system that reflects at least one type of structural relation between at least two elements. Besides that a model reveals structural relations of its object, the profound purpose of a model is to be portable - to overcome the limits of space and time that block users' access to the object itself. That is, of course, the deepest cause and purpose of any sign use.

Returning to film trailers, we must first admit that a trailer is a complex model of thousands of conceivable elements and relations. To come to grips with this complexity, it is helpful to recall that the model is able to substitute for the original only in some functions (Tondl 2000: 85) and ask what are the most decisive properties of the film that the trailer is modelling. I propose that the trailer models the future experience of film or film viewing. That future experience can be presupposed, having a previous knowledge about a certain "analogy" between the trailer and the film. This analogy rises from the correlation between elements of a model and its object. Tondl points out that if models represent only a selected set of elements, attributes or functions of the original, the selection procedures have the fundamental role in model-making (Tondl 2000: 86). Thus, I will next examine how elements are selected for film trailers.

For Kernan, the core process of meaning generation in a trailer is editing (Kernan 2004: 13). Constructing a trailer as a model on the basis of film involves alternation, combination and abbreviation of scenes. This process generates a new trailer logic, differing from the narrative logic of the film. One shot in a trailer is called upon to refer to various narrative elements, such as character subjectivity, relations between different characters, plot development and suspense (Kernan 2004: 10). Editing is a powerful tool for model-making. It breaks the film's syntagmatic and paradigmatic connections, joins elements with new contexts and is able to connect, in the new virtual space of trailer, the same signifiers with new signifieds.

As Johnston observes, modern editing demonstrates new complexities in techniques, often speeding up the pace of cutting and concentrating information in ways that often make it difficult for the viewer to obtain a sufficient understanding of the film's narrative (Johnston 2009: 137). As stated by David Bordwell, the editing tempo of Hollywood feature films has at least doubled or tripled, depending on the genre, since the 1960s. The new style has become more elliptical. For the sake of intensity, filmmakers tend to omit some of the built-in redundancies of classic continuity editing style. This means, for example, using fewer establishing shots and more frequent shot-reverse shot exchange in dialogue scenes (Bordwell 2002: 17). The changes in film editing have influenced both trailer-editing and trailer-viewing practices. Closer inspection of this topic remains outside of the focus of this article, but it would be an interesting field of research. 
Nicola Dusi's view of trailer-making as intrasemiotic translation, introduced above, emphasizes that the trailer is represented in the same "language" or sign system as the film. Thus, a trailer as a model is made of the same material as its object; by the means of re-editing film shots and combining them into a new syntagmatic organization. This fact obviously complicates the question of the trailer's authorship. As was also pointed out above, trailer-making can be seen as a negotiation between different agents. An explanatory framework to this process is offered by remix studies.

Martin Irvine, whose approach expands on Bakhtin's concept of dialogism, sees generative dialogic principles behind all types of remixes. According to Irvine, techniques of composition (collage, assemblage, music remix), artistic practices, media and technology hybridization can be summarized with the term of combinatoriality (Irvine 2015: 15-16). For Irvine, the phenomenon of remix is connected to Peirce's concept of infinite semiosis, where meanings unfold in openended, unlimited sequences. Hence, the necessary structure of the human semiotic process is always dialogic (Irvine 2015: 19). No meaning is ever finally fixed, the property of being remixable or remixed has always belonged to any text, and any action of meaning generation is thus committed by multiple parties.

Remix studies offer a great philosophical context for the trailer's construction process, preventing exaggerated debates over the authorship of the trailer. Nevertheless on the level of textual poetics, it is constructive to complement remix studies with the notion of multimodality. Both remix and translation in their conventional sense assume a single mode. Obviously, the film and the trailer use various modes at the same time. These different modes can become asynchronous with one another or go through different types of transformations in parallel. For example, the trailer may feature the same shots as the film, but employ some additional soundtrack, voice-over or graphics that the film does not. Therefore the modelling process in trailer-making is conducted on several modal levels, and it requires a certain meta-skill, an ability to coordinate between different modes.

According to Carmen Daniela Maier, who follows the ideas of Kress and Van Leeuwen, in multimodal text meanings are produced through the interaction and intersection of different modes (Maier 2009: 161-162). Maier admits that trailers as multimodal texts communicate their promotional messages through numerous modes and submodes, but she generalizes these into three main modes: the verbal, the visual and the aural mode (Maier 2009: 164, 162). I propose that the dominantcentred analysis can also be extended to the interaction of modes. As it enables to see a hierarchy in the system of meaning generating devices, it helps us recognize which of the main modes becomes dominant in a specific context, e.g. in a shot. The dominant mode will coordinate and determine the representation potential of subordinate modes. 
I propose that the coordination between modes works atypically in a deceptive trailer. My working hypothesis is that while in a "reliable" trailer all modes work in accordance with one another, in a deceptive trailer different modes would present conflicting information about the film's genre. For that reason, I consider the deceptive trailer to be an especially interesting object of study from the viewpoint of multimodal analysis. A closer analysis below will test the hypothesis of the conflicting modes and exemplify the meaning generation mechanism characteristic of the deceptive trailer.

\section{Deceptive trailers: A case study}

\subsection{The measure of discordance: From the trailer's elliptical character to intentional cheating}

For most authors it is obvious that trailers create a narrative time-space that differs from the fictional world of the film. As its main function is advertising, a trailer tends to present the most attractive and emotional details of the film. According to Kernan, trailers are little stories in which codes of narrative fiction are transformed into codes of promotional rhetoric. Images are selected and combined in ways that privilege attracting the spectator's attention, rather than sustaining narrative coherence. Often, the most spectacular features such as intensive action sequences, explosions and car crashes are emphasized (Kernan 2004: 7-11). As a model, representing only some of the features of its object, the trailer omits much of the information that expands and diversifies the viewing experience of the film.

Doing this, trailers can suggest plot developments that are false, or contain conversations that never happened (juxtaposing two lines of dialogue that are not adjacent in film). Trailers can detach spoken lines of dialogue from narration and insert these as voice-overs, providing false narration. Sometimes trailers utilize shots that do not appear in the finished film (Kernan 2004: 11). Yet these criteria alone are insufficient to consider a trailer as deceptive. The deceptiveness of a trailer is a subjective quality that is disclosed by the analysis of reception. One of the key indicators would be the disappointment of viewers, who feel a dissonance between the film and its trailer. This dissonance gets a suggestive expression in the comments under the trailer's online representation, and the commenting possibilities on YouTube and similar sites afford new reflexive material for researchers.

Subsequently, I will analyse the relations between two films and their trailers, Alejandro González Iñárritu’s Birdman and Nicolas Winding Refn's Only God Forgives, starting with a brief detour to the comments of their trailers. The choice 
of the films is subjective and based on my personal viewing experience. I selected films that stood out as regards the discordance with their trailers, which led to the feeling that the objects did not correspond to the expectations that their models created. In the present article I do not intend to discuss the question of value. It does not matter if the film is considered better or worse than expected. During film viewing, the discordance between the trailer and the film can also turn out as a pleasant surprise. Still, most online comments that refer to the discordance tend to be rather negative. The following examples come from among YouTube commentaries on the trailer of Birdman, posted on this social media platform ${ }^{11}$ :

(1) Kiko Gonzaga: i cant believed this movie won an award.....i cant even stand 10 minutes watching this..so boring!

(2) sinnerfire: So does he have super powers or is it just in his head?

(3) SalivaSpit Acid: I thought this movie is something like marvel or dc.

All three comments clearly reflect some level of discordance. (1) and (3) express disappointment with the film; recognition in (3) is closely related to the false expectations obviously created by the publicity; (2) expresses confusion about the film's diegetic world. Confusion expressed in (1) and (2) can also be seen as caused, at least indirectly, by the misguided expectations of genre.

\subsection{Detecting dominants in films and trailers}

Specifying the film's genre requires some pre-established codes, and these codes, in turn, require mutual agreement between viewers, film-makers and distributors. Thus, it is a partly subjective activity in which objectivity arises from the sum of subjectivities.

The more detailed question as to how viewers recognize genres is a complicated one. We can follow Barry Keith Grant who evokes Aristotle's classical observation, adjusting it to film. He infers that recognition of genres is possible due to the common elements that allow a number of films to be grouped together and conceived of as a category (Grant 2007: 4). On the one hand, how viewers detect similar elements that are present in a variety of films and see them as the markers of genre is a rewording of the previous question. On the other hand, it is a key towards the description of cognitive processes that act as foundations for detecting the normativity of textual codes.

Here, I can only propose that almost any element or device in film (from the choice of an actor to camera angles), depending on its context, can work as a

11 The trailer is available at https://www.youtube.com/watch?v=uJfLoE6hanc (accessed 18 November 2017). 
marker of genre. I also propose that elements which are felt to be significant about the film's dominant stand out in at least one of the four major aspects: (1) they take up a remarkable amount of the film's running time; (2) they connect to the viewer's emotions; (3) they are essential to the progression of the film's narrative; (4) they are positioned at the beginning or the end of the film. In a trailer, all these parameters are compressed. As the narrative dimension is reduced in a trailer, I propose that it is the first and the last aspects that are crucial for the trailer. The time limit of the trailer is critical ${ }^{12}$, thus the second by second distribution of elements inside the trailer's two-to-three minutes' running time plays an essential role in the matter of detecting the dominant.

\subsection{Trailer analysis: Disclosed discordances}

\subsubsection{Birdman}

The following presents a qualitative analysis of the trailers of Birdman and Only God Forgives, discussing how specific genres are suggested by various filmic codes or devices of meaning generation. I will point out how similar elements can suggest different genres in a film and its trailer. As the subjective position of the observer is always the ultimate locus where the semiotic relation between the film and its trailer is fixated, I will also refer to some user comments from the trailers' YouTube pages, regarding these as reflexive metatexts. The multimodal relationships between the visual, the aural and the verbal modes will also be paid attention to.

The length of Birdman's trailer is two minutes and 52 seconds. The first shot lasts for ten seconds and opens inside the darkened room of the main character Riggan Thompson. The protagonist (played by Michael Keaton) is hovering motionlessly in the air in a meditation pose. His back is turned towards the camera and his face cannot be seen. He is clad only in underpants. Camera slowly moves in, towards his back. Then voiceover, a coarse, slow male voice says: "How did we end up here? This place is horrible. Smells like balls". The accompanying music carries the theme of moderate anticipation.

If the trailer is seen in its natural viewing situation, i.e. without having seen the film, the viewer may only assume that the man shown in the first shot is

12 Viewers' attention span plays a significant role here, too. We can suppose that in film viewing, emotion-inducing capabilities of various elements are more important than in trailer viewing. Throughout the trailer's brief duration, the viewer's attention stays constantly high and emotions are not primary in drawing attention to the trailer's elements. Nevertheless, emotions have other, closely related functions, e.g. helping to memorize the trailer's elements and retrieve these accordingly during film viewing. 
the protagonist. It is also unclear who is saying the opening words. The plural pronoun 'we' in the voiceover has a slightly estranging effect: it makes us doubt that the inner monologue belongs exclusively to the protagonist. A moderate interaction of modes may emerge from the verbal mode and the code of costume: the character's old-fashioned underwear pants and the word 'balls' can give rise to a slightly comic effect. Still, the mysterious mood conveyed by the visual mode is prevailing (leading to the connotation of the protagonist's supernatural powers) and casting its meaning over the remaining part of the trailer.

After the first cut the production company logos are shown and the music changes towards a more optimistic, but still fairly minimal arrangement. The editing speeds up, during the next 50 -seconds thematic block the average shot length is approximately two seconds. Different voiceovers, male and female, are combined with diegetic verbal texts. They convey that the protagonist used to be a movie star, playing Birdman; he adapted a theatre play, struggling to direct it and star in it; he said no to performing in Birdman 420 years ago; now he is going to destroy what is left of his career. The accompanying visual material conveys the protagonist's nervousness and anxiety, culminating in outbursts of anger. A fistfight between the protagonist and another man is shown; yet another man falls down from chair, his head violently smashed by some object. The shot is too short to recognize who the man is and who or what hit him. On the 53rd second of the trailer's duration, the second supernatural episode takes place: Thompson breaks light bulbs with the sheer power of his mind combined with a mighty hand gesture in the air.

According to the first impression, the verbal text has all the details that are needed to re-construct (or rather pre-construct) the basic aspects of the film's plot. Still, the episode with lightbulbs enforces the belief in the presence of superpowers. We cannot infer this on the exclusive viewing experience of the trailer, but only in analysis after seeing the film, that visual and verbal modes, once again, work against each other. Because of the conflicting sign use, no clear-cut impression of a specific genre is presented and the viewer is left confused.

The highlighting of the violent episodes is very common to the semiotic strategies of contemporary trailers. As Kernan and others have hinted ironically, more often than not most action-esque episodes of the film are piled up in the trailer, to leave the impression that the whole film consists of similar scenes.

The next thematic block starts approximately at one minute of the trailer's time. The soundtrack features a dramatic piano tune with a young woman's voiceover: "Face it, dad, you're doing this because you are scared to death like the rest of us that you don't matter. And you know what - you're right! You don't!". Then the face of the girl who said this is shown. Subsequently Thompson walks out of the room and Brent Smith's version of Nina Simone's 1964 song “Don’t let me 
be misunderstood" starts to play, suggesting romantic solitude and sadness. The corridor into which Thompson steps is overwhelmed by unnatural blue light. As the camera moves in along the corridor, some stylized, unreal-looking birds are seen flying far away, as is a tree without leaves and a woman standing in the fog. The title "An Alejandro G. Iñárritu film" appears for 3-4 seconds. The camera zooms in on the woman and makes a turn around her. With attentive viewing, it is possible to recognize a theatre stage behind the woman, but the overall mysterious atmosphere stills suggests some fantastic place, a locus not for a drama but a film of a different genre. For comparison, in the film we can see that this sequence continues with the theatre stage emerging in its own right.

Then, after a visual dissolve, the romantic theme is abruptly broken off and we encounter Thompson in the street, walking towards the camera with a determined look, his face in close-up. The coarse voice from the beginning of the trailer urges him: "Let's make a comeback!" Then Thompson snaps his fingers in the air, the camera turns left and shows a car running into the wall with a bang. After that, the camera turns up towards the sky where two military helicopters are hovering. Something flashes in the air and hits one copter with an explosion. "That's what I'm talking about," the voice says encouragingly. Next we can see big dark bird wings emerging from behind of Thompson. Then the scene is abruptly cut and the camera is looking upwards, where a giant CGI-generated fantastic bird jumps into flight from the roof of a building. "You're Birdman. You're a God," the voice says. Then a quick action sequence follows in which a house explodes and a helicopter blasts its machine guns. The action sequence lasts about 10 seconds altogether.

In my opinion, the scene with the emerging bird wings conveys the most significant point of the trailer in the sense of genre and meaning generation. The editing ultimately dictates the impression the viewer gets. In the trailer, the shot is cut precisely in the manner that allows us to see only the wings behind Thompson. In the film, there is, vice versa, a man, the true owner of the voice, walking behind Thompson. While he is giving similar suggestions as the voice in trailer, he is clad in a fantastic bird costume. Significantly, in the film, there are many people in the street, constantly walking by, but not spotting the weird man in the bird costume. This is a clear message to the viewer that this peculiar companion only exists in the protagonist's fantasy. In the trailer, this marker is intentionally omitted, leaving the impression that Thompson himself will immediately turn into a human-bird hybrid.

Next, the trailer continues with Thompson standing on the roof of a building, while a woman's voice is shouting from the neighbouring roof, "Is this for real or you're shooting a film?" "A film," Thompson answers. "You people are full of shit," the woman rants back. 
This, again, is a playful approach to the viewer's perception, setting two modes against each other. Seemingly, the viewer has a choice between two contradicting things to believe: the visual image and the spoken text. I would strongly suggest that the visual component is overwhelming in this case. The visual is further reinforced in the following, where Thompson says "Music" in a commanding manner and an uplifting symphonic piece commences in the soundtrack. Then Thompson vigorously jumps off the roof as a bird and the camera cuts to the admiring close-up face of his daughter. Then a falling and flaming comet is shown, then theatre corridors full of journalists and photographers. The dialogue from supporting characters lets us know that "Thompson is a Hollywood clown," yet he is "going out on that stage and risking everything." "I got a chance to do something. I gotta take it," claims Thompson. Meanhwile, quick editing flashes through the shots that may be considered as emotion-evoking for wide audiences: two women kissing, a gun pointing to a head, and costumed drummers announcing the beginning of a show. The shots are cut, a couple of times, to naked Thompson walking enthusiastically across a city square in the midst of shouting people. At 2.20 animated credits appear, presenting the film title and the actors. After that, the trailer once more cuts back to naked Thompson giving an autograph to a fan. Finally, company credits of the film, festival selection announcements and the film's webpage address appear.

The final sections confirm that the trailer follows the classic logic of the narrative: the hero finds himself in a difficult state, faces challenges ahead, but, getting help from supernatural powers and gaining some fortitude, struggles on. The end of the trailer leaves the character waiting for the final ordeal, appealing to the viewer's curiosity and inviting us to watch the film, promising to provide a closure. That promise depends on the narrative code that is omnipresent in fiction film, being common to both of the suggested genres, superhero fantasy and satirical drama.

It is important to note that the narrative code is too general and omnipresent to be a dominant itself. In any case, appealing to narrative means appealing to familiarity, assuring the viewers that a customary story is waiting ahead. In Birdman's trailer, the narrative code works as a sort of safeguard, guaranteeing that the trailer will not completely fail: like a good liar, it inserts a portion of truth into the discourse. Consequently, the lie of the trailer has a better success rate with the help of a parallel truth-telling code.

The deceptive meaning generation is performed, instead, on the level of the genre, playing two possible dominants - Marvel-style superhero action and realistic drama - against each other. The superhero action genre prevails, for it 
is conveyed visually, through the most powerful modality ${ }^{13}$. The signs of satirical drama (the genre of the actual film) are mostly hinted through the dialogue, which remains in a secondary position in this trailer. Alhough some comic elements (e.g. the nakedness of Thompson) are presented in the visual modality, they cannot ward off the superhero-oriented impression. This is created with the careful positioning of the supernatural episodes and a significant amount of the trailer's time being spent on these. In the film, the supernatural passages are hugely outnumbered by sequences that, in the sense of the genre, belong to satirical drama, and as indicated above, their context reveals that they only happen in the protagonist's imagination. Moreover, the trailer carefully avoids giving any clue that the supernatural "companion" is just a voice in Thompson's head, not a character existing in the diegetic world.

I suggest that confusion about and disappointment at the film's genre can irritate viewers. It urges the viewers, at least those who prefer superhero films to realistic dramas, first to watch and then hate the film. Or, as YouTube comments indicate, when a viewer prefers dramas to superhero films, the reaction can turn against the trailer (Ryan Homcy: "This trailer does the movie absolutely zero justice and it's not worth watching if you're at all interested in watching the movie"). In order to understand the intentions behind replacing the dominants in the trailer, one must consider that sophisticated humour and insights into Broadway acting may prove a difficult topic for wide audiences. Superhero films, on the contrary, are generally easily digested, and have been box office hits in the last two decades. Thus, the deceptive modelling in the Birdman trailer is mostly a marketing calculation that $(\mathrm{p})$ represents the object as a product under a more popular category than it actually belongs to.

\subsubsection{Only God Forgives}

The other trailer observed is less radical in its deceptive strategy. While Birdman was presented as belonging to a totally different genre, the trailer of Only God Forgives rather suggests variations inside a single genre. Nevertheless, dissatisfied commentators highlight the fact that this trailer has created expectations that were not sufficiently fulfilled by the film. A comment by user 'dan hackett', under the trailer of Only God Forgives ${ }^{14}$, from Youtube: "What a load of shit seemed like

13 A major amount of the brain's processing power is dedicated to visual processing. As Kahneman and other cognitive pshychologists show, the tendency to believe what we see before doubting is a strong thinking bias of the human species (Kahneman 2011: 81).

14 An international trailer is available at: https://www.youtube.com/watch?v=Dkc7htnHrg0 (accessed 20 January 2018). 
it was building for a great fight but no absolute bullshit ending". Or by the user 'hypp', also from Youtube: "Poor guy who made this trailer, i think he got fired".

This trailer is shorter; it runs for one minute and 21 seconds. As the first comment said, with its storytelling this trailer "builds for a fight". During approximately the first 25 seconds it presents the protagonist Julian (Ryan Gosling ${ }^{15}$ ) and, mostly via verbal mode, gives us various pieces of information, allowing us to understand the problem situation: Julian's brother has been killed and the mother of the two sons (Kristin Scott Thomas) is giving a forceful order to take revenge. She says, "If the tables were turned, your brother would have found your killer and brought me his head on a fucking platter!" In her line of the dialogue in the trailer, the grammatical mood of the phrase "brought me his head on a fucking platter", could easily shift towards the imperative due to the pragmatical context. In the film, however, the purpose of this dialogue is rather to convey the troubled relationship between Julian and his mother: the mother's dominating and humiliating power over Julian can be discerned.

When the mother finishes her line and slams her fist on the table, the trailer is cut to the antagonist, "the killer", an ominous middle-aged police officer called Chang. This time, different modalities support each other. The next shot shows Julian dramatically snapping the cylinder of his revolver to its place (more than a hundred years of film history has codified into this movement the indescribable feelings and connotations that accompany a protagonist's determination to step into fight). Then the first title fills the screen: "From Nicolas Winding Refn, director of Drive", and electronic music intensifies, suggesting tension.

In the next shot Chang is shown wielding a sword and slashing downwards with it, but the victim is not shown. We can hear a splatter of blood in the soundtrack. Then Julian is standing in a corridor lit in red light, two motorcycles are driving along a street at night, and a gangster-looking killer is shooting people in a canteen. At this point, another slight discordance may be spotted between the film and the trailer. The origin of the shooter is left ambiguous in the trailer and the viewer may consider him as a "bad guy", but in the film he actually belongs to the same side as Julian. As a matter of fact, this is a simplified conception. In reality, Refn's film, rather unconventionally for Hollywood, sets out to deconstruct the boundary between good and evil. This is the main quality that the model-making in this trailer hides. The relationship between Julian and the officer Chang is not exactly a classic conflict between the hero and the antagonist.

15 Speaking of Gosling's previous acting assignments, a lawsuit has reportedly been filed over the misleading trailer for another film of Refn's, Drive (http://gawker.com/5847970/womanfiles-lawsuit-over-misleading-trailer-for-drive). 
Though Chang forebodingly appears in Julian's visions, and brings along a lot of unflinching violence in reality, he stays calm and righteous in a sense, representing an equalizing force from the viewpoint of society and justice. As we learn in the course of the film, Julian himself will come close to the status of an antihero.

Then the editing speeds up for 10 seconds, presenting quick shots, each lasting approximately a second. In a quick succession we will see Julian's mother, Julian in a close-up, a beautiful girl, Chang wielding a short sword, an unidentified man clenching his fists as if in fury (in the film we shall realize that this is Julian), etc. The music is dramatic and nervous. At 00.50 the music subsides and a shot-reverse shot dialogue between Chang and Julian is presented. Julian asks, "Wanna fight?". Then, without any answer being given, the music becomes loud and aggressive again; in a restaurant or cabaret, Chang brutally assaults a sitting man. At this point, the title "Ryan Gosling" with characters in the Thai language underneath it is shown briefly. The editing, once again, speeds up to one-second cuts, featuring a man shooting a mini-Uzi, the antagonist with a sword, fighters in a Thai boxing ring, a woman's wrists being tied, Julian, his mother; and in the midst of these shots, the names of Kristin Scott Thomas and Vithaya Pansringarm (the actor playing Chang) briefly appear. All these shots are only loosely connected to the trailer's narrative progression, amplifying the images and emotions of the previous quickly edited succession.

The next shot develops the narrative further (repeating, in a way, the theme with Julian's revolver). At 1.06 we see Julian, clad in an elegant shirt and a suit waistcoat, slowly rising his fists. Previously, snapping the revolver's cylinder conveyed at least some distance with the enemy. The commencing fistfight hints the enemy's close presence and an immediate clash. Then we can see Julian attacking Chang and being punched (but not falling). The scene is instantly cut back into the Thai boxing ring that we have glimpsed before, and an anonymous fighter falls from the other's blow. In such a manner, two locations and actors are joined in a symbolic whole, alluding to Julian's probable fall. The fighting moves of Julian are taken from the second half of the film; the falling boxer from the beginning. Then, the music subsides again, and an unidentified man says, "Time to make a double" (in film, this man is revealed to be Julian's brother). Mixed with the title of the film, Chang is seen slowly emerging from a door towards the camera. The music subsides and the trailer more or less ends with the title "Coming soon".

It is not clarified what the man means by "making a double", but it may indicate a retake, or a more successful attempt, in the context of the trailer's own narrative. Clearly, it is promised that this "double" or a more successful attempt will appear in the film. In the unwritten sign system of the trailer, a sense of anticipation is usually left in the air, and the viewer is invited to experience the film mostly to see 
how the hero takes real revenge. In the next imaginary "double", projected onto the future film-viewing experience, the hero is supposed to be winning.

Refn's film, on the contrary, does not fulfill this promise. The last 10 minutes of the film are governed by Julian's resignation. The likely hero is devastatingly beaten up in a fistfight with Chang. Once again, the Oedipal background of Julian's story is confirmed, and a symbolic episode with his mother's dead body takes the viewer even further from the anticipated codes of mainstream action. Julian's downfall culminates with Chang mutilating his hands with the sword, just as Julian's visions had foretold. In a way, the film still allows Julian to be a hero in a subtle sense, with his decision to kill his companion in order to save the life of Chang's daughter. Nevertheless, this redemptional (Julian's guilt is removed by removing his hands) and self-denying way of heroism is not coded into the genre expectations of action film with revenge as its main theme.

In Only God Forgives, the shift of the dominant between the film and its trailer occurs on the level of subgenre. The trailer creates expectations for a dynamic, digestible and fulfilling action film, yet Refn's work turns out to be a stylished arthouse film, much more demanding towards its viewer. A suggestive soundtrack and expressive direction of photography help create a foreboding and dreamlike diegetic world in which the expected hero-image is cleverly deconstructed at the end of the film. The boundary between hero and anti-hero is dissolved, and a deep human tragedy is revealed. The critical response to this film was highly divided: some loved the film and many hated it. I suggest that at least a part of the negative response was caused by the false expectations that the trailer created, and by the disappointment that followed.

\section{Conclusion}

The purpose of the article was to offer a framework for the semiotical analysis of paratext, and to discuss how a specific paratext (film trailer) influences the meaning of the main text (the film itself). The relation between the text and the paratext was seen as a relation between an object and its model. The article advanced a functional definition of the model that lets its user perform systematic cognitive operations that can materially or virtually be transferred to the model's object. In the optimal case for viewers, the trailer would make it possible to preconstruct a truthful experience of the forthcoming film. In the optimal case for the marketing establishment, the trailer would present the film as attractively as possible. However, there is a conflict between these two functions, clearly exemplified by the phenomenon of deceptive trailers. 
While trailers aim to present the most attractive components of films, deliberately deceptive promotion occasionally occurs. As Kernan and Johnston have shown, the sales message or rhetorical application of the trailer is mostly built around the genre, a film star or, in some cases, technological innovation. In the two deceptive trailers that were analysed in this article, the most fundamental organizing principle was genre. The phenomenon of the deceptive trailer emerged when a film tended to be difficult to categorize in terms of genre, significantly deviating from the codes that communicate its genre or subgenre (Only God Forgives), appearing too intellectual for wide audiences (Birdman) or over-stylized for the taste of audiences and not sufficiently benevolent towards its hero (also Only God Forgives). In these cases, the trailer advertised the film as a text that addresses its audiences through more simple and familiar codes.

The fundamental concept for the analysis was Jakobson's notion of the dominant. The concept of the dominant helps to reveal the organizing principles in model-making, discerning the trailer's pivotal elements, and describing how they manage, determine and transform other components. It is possible to compare the dominant of the film and its trailer, in order to reveal the discordances in the process where trailer communicates the genre of film. Jakobson's definition of the dominant allows us to approach genre on two levels. First, as was noticed in both analysed trailers, genre in a general sense functions as the dominant of the trailer, subordinating and organizing the trailer's actor- and technology-based cues. Second, genre in a specific sense, i.e. action, drama, comedy and so forth, partly organizes the material on the level of the film and concurrently pre-organizes it for the trailer. On both levels, genre structures the process of trailer production as model-making.

The analysis disclosed how multimodal construction of the trailer could shift the perception of the film's dominants. In the trailer of Birdman, different modes contradicted one another, but the visual mode as the most influential one imposed its meanings and let the film's genre be falsely read as Marvel-style superhero action instead of a satirical drama. It can be inferred that multimodal modelmaking has the potential to enhance the deceptive effect. If all modes suggest a single dominant, the impression of the genre would be strong and straightforward, but the deception (should the genre of the film actually be different) would be too obvious and inexcusable. Constructing a promotional model of a product with the help of slightly contradictory modalities that still suggest one dominant is a subtler way of advertising. It lets the advertiser escape the accusation of blatant lying.

We can suppose that due to its time limits the film trailer has a narrower range of possible dominants than the film itself. Because of this, it is difficult to transform some film dominants into trailer dominants. Instead, they are often 
concentrated, translated, replaced or omitted. Apparently, when the dominants of the trailer and the film do not match, viewers are inclined to compare film with the promises given by its trailer. In my opinion, the viewers' cognitive reactions would be the next crucial spot in further studying of the working mechanisms of film trailers.

The question whose reputation gets damaged or whose social capital diminishes because of such deception is also crucial. Among other advertisements, the trailer has a greater opportunity to deceive because it sells a product with a relatively short lifetime (the film's running span in the cinemas), usually meant for a single use or viewing. If the actual form and themes of a film are not easily explicable in the common genre codes, the temptation arises to simplify them, or it is attempted to sell "difficult" films under different, more popular labels. This is a sensitive issue in film marketing: creating a deceptive trailer can temporarily boost a film's sales, but in the worst cases it may damage the actors' or the director's career. The question is if the reputation of film studios faces a similar danger.

I suggest that who wins or loses in the end will mostly depend on the audiences' standpoint on the authorship of the film. It depends on how the audiences answer to the questions: Whose film are we watching? Who is communicating the film to us? and, Who is deceiving us by selling us a "false" product? The question how the audiences imagine their invisible partner or adversary in film viewing and, more generally, in other acts of consumption, is of interest also for marketing and media semiotics. ${ }^{16}$

\section{References}

Aitken, Ian 2001. European Film Theory: A Critical Introduction. Edinburgh: Edinburgh University Press.

Altman, Rick 1999. Film/Genre. London: British Film Institute Publishing.

Bakhtin, Mikhail 1981. Discourse in the novel. In: The Dialogic Imagination. (Holquist, Michael, ed.; Emerson, Caryl; Holquist, Michael, trans.) Austin: University of Texas Press, 259-422.

Baldry, Anthony; Thibault, Paul J. 2006. Multimodal Transcription and Text Analysis. London: Equinox.

Bordwell, David 2002. Intensified continuity: Visual style in contemporary American film. Film Quarterly 55839: 16-28.

Dusi, Nicola Maria 2015. Remixing movies and trailers before and after the Digital Age. In: Navas, Eduardo; Gallagher, Owen; burrough, xtine (eds.), The Routledge Companion to Remix Studies. New York: Routledge, 154-165.

16 Acknowledgements. This article was written within the framework of project PRG314 of the Estonian Research Agency. 
Eikhenbaum, Boris 1975[1927]. Problems of cine-stylistics. In: Shukman, Ann; O’Toole, Michael (eds.), Russian Poetics in Translation. Vol. 9. Colchester: The University of Essex Press, 5-31.

Eisenstein, Sergei 1988[1923]. The montage of film attractions. In: Selected Works. Vol. 1: Writings, 1922-34. (Taylor, Richard, ed.), London: BFI Publishing, 39-58.

Irvine, Martin 2015. Remix and the dialogic engine of culture: A model for generative combinatoriality. In: Navas, Eduardo; Gallagher, Owen; burrough, xtine (eds.), The Routledge Companion to Remix Studies. New York: Routledge, 15-43.

Genette, Gérard 1997. Paratexts: Thresholds of Interpretation. Cambridge: Cambridge University Press.

Grant, Barry Keith 2007. Film Genre: From Iconography to Ideology. London: Wallflower Press.

Gray, Jonathan 2010. Show Sold Separately: Promos, Spoilers and Other Media Paratexts. New York: NYU Press.

Grzybek, Peter 1994. The concept of 'model' in Soviet semiotics. Russian Literature 36(3): 285-300.

Jakobson, Roman 1959. On linguistic aspects of translation. In: Brower, Robert A. (ed.), On Translation. Cambridge: Harvard University Press, 232-239.

- 1981[1935]. The dominant. Selected Writings III. Poetry of Grammar and Grammar of Poetry. The Hague: Mouton Publishers, 751-756.

Johnston, Keith M. 2009. Coming Soon: Film Trailers and the Selling of Hollywood Technology. London: McFarland \& Company.

Kahneman, Daniel 2011. Thinking, Fast and Slow. London: Penguin Books.

Kernan, Lisa 2004. Coming Attractions: Reading American Movie Trailers. Austin: University of Texas Press.

Lotman, Yuri 1977. The dynamic model of a semiotic system. Semiotica 21(3/4): 193-210.

- 2006. Kunstilise teksti struktuur. Tallinn: Tänapäev.

- 2011[1967]. The place of art among other modelling systems. Sign Systems Studies 39(2/4): 249-270.

Maier, Carmen Daniela 2009. Visual evaluation in film trailers. Visual Communication 8(2): 159-180.

McHale, Brian 1987. Postmodernist Fiction. London: Routledge.

Nöth, Winfried 2018. The semiotics of models. Sign Systems Studies 46(1): 7-43.

Stam, Robert 1992. New Vocabularies in Film Semiotics. New York: Routledge.

Thomas, Kevin 1966. Movie trailers have long runs. Los Angeles Times, Oct. 25, 10.

Tondl, Ladislav 2000. Semiotic foundation of models and modelling. In: Bernard, Jeff; Grzybek, Peter; Withalm, Gloria (eds.), Modellierungen von Gescichte und Kultur. Modelling History and Culture. Band I/Vol. I. Wien: ÖGS, 81-89.

Torop, Peeter 2002. Translation as translating as culture. Sign Systems Studies 30(2): 593-604.

Tryon, Chuck 2009. Reinventing Cinema: Movies in the Age of Media Convergence. New Brunswick: Rutgers University Press.

Tynjanov, Yuri 1982[1927]. The fundamentals of cinema (O’Toole, Lawrence Michael, trans.). In: Shukman, Ann; O’Toole, Lawrence Michael (eds.), Russian Poetics in Translation. Vol. 9. The Poetics of Cinema. Colchester: The University of Essex Press, 32-54. 


\section{Введение в заблуждение трейлером: трейлер фильма как паратекст и мультимодальная модель}

Цель статьи - разработать теоретические основы семиотического исследования трейлера фильма. Рассматривают ситуацию, где трейлер или паратекст действует как модель фильма или текста, оказывая влияние на прием фильма. Опираясь на работы Кернана и Джонстона, трактуют жанр фильма как главную передаваемую информацию трейлером. Рекламируя фильм, трейлер указыает на жанр часто неопределенно или вводя в заблуждение. В статье анализируют трейлеры фильмов “Бёрдмэн” Иньярриту и “Только Бог простит” Рефна как примеры обманчивого мультимодального моделирования. В качестве начального понятия используют понятие доминанты Якобсона. Методика на этой основе позволяет определить доминанты трейлера (модели) у фильма (объекта), а затем их и сравнивать.

\section{Eksitav treiler: filmitreiler kui paratekst ja filmi multimodaalne mudel}

Artikli eesmärk on arendada teoreetilist raamistikku filmitreileri semiootiliseks uurimiseks. Vaadeldakse olukorda, kus treiler ehk paratekst hakkab tööle filmi ehk teksti mudelina, kujundades filmi retseptsiooni. Tuginedes Lisa Kernani ja Keith M. Johnstoni töödele, käsitletakse filmi žanri kui peamist treileri poolt edastatavat informatsiooni. Filmi reklaamides viitab treiler žanrile sageli ebamääraselt või eksitavalt. Artiklis analüüsitakse Alejandro G. Iñarritu „Lindmehe” ja Nicolas Winding Refni „Ainult Jumal andestab” treilereid kui näiteid eksitavast multimodaalsest modelleerimisest. Teoreetilise alusmõistena rakendatakse Roman Jakobsoni dominandi mõistet, millel põhinev metoodika võimaldab määrata treileri (mudeli) ja filmi (objekti) dominandid ning neid omavahel võrrelda. 